\title{
Enzymes and industry: A tasty compendium
}

Industrial Enzymology, Second Edition, Tony Godfrey and Stuart West (eds.). Macmillan Press, Basingstoke, UK, 1996, pp. 609, £110.00, (hbk).

\section{Bruce P. Wasserman}

In today's world of enzymology, business is booming, but the impetus is not entirely profit driven. As the global population approaches 6 billion, agriculturally productive acreage has remained constant, or has declined because of intense developmental pressures. To keep pace with the demanding global marketplace, new and efficient ways are needed for production of raw agricultural commodities and ingredients, for processing and for biopolymer modification. Dependence upon petrochemicals and energy-intensive processes must be minimized. Biological catalysts are ideally suited for these purposes. Accordingly, the current edition of Industrial Enzymology, which triples the content of its predecessor, serves as a testimonial to the explosive growth occurring in the adaptation of enzymes for commercial processes.

Since publication of the first edition in 1983, a multitude of new or second genera-

Bruce P. Wasserman is at the department of food science, Rutgers University, New

Brunswick, NJ 08903-0231

(wasserman@aesop.rutgers.edu). tion industrial applications have emerged. In all, the 22 contributions comprising the second section focus on detailed descriptions of varied product areas encompassing food, feed, fuels, textiles, detergents, pharmaceuticals, and analytical applications. Additional chapters cover regulatory aspects, toxicological considerations, and safety in handling enzymes. The remaining $20 \%$ of Industrial Enzymology contains six data indices, including a comprehensive list of enzyme suppliers, trade names, and operating characteristics for specific products. Although these lists are continually changing and tend to be somewhat redundant in places, they provide a useful starting point for anyone contemplating use of a specific enzyme system. Perhaps such information could be continually updated by electronic means.

The principal take-home message from Industrial Enzymology and other volumes devoted to this topic may well be that the commercial side of enzymology is as much an art as a science. The proprietary nature of this industry lends itself to an atmosphere where no fixed set of hard-and-fast rules applies, necessitating development of new decision trees as each new process and enzyme is introduced. As such, much information in this field tends to be experience-based, seldom reaching peerreviewed journals. Amassing multiple authors from a range of organizations therefore fills a void and defines a common theme. A series of complex benchmarks must be met for any enzyme-catalyzed industrial process to succeed. Ultimately, the unique advantages of each application must effectively outweigh the technical hurdles encountered during enzyme characterization, optimization, and scale-up. Although the value of emerging technologies such as protein engineering are recognized, Industrial Enzymology is oriented toward enzyme use rather than production.

The second edition of Industrial Enzymology fills a critical niche and should appeal to a wide readership. In light of the fact that thousands of enzymes have been characterized, but only several dozen are currently used commercially, future opportunities pertaining to the use of enzymes, ribozymes or even antibody-based catalysts, especially in frontiers such as organic synthesis, should flourish. Industrial Enzymology will serve as a vital and necessary reference source for specialists and nonspecialists alike.

\section{Furniture for the shelves?}

Industrial Enzymology, Second Edition, Tony Godfrey and Stuart West (eds.). Macmillan Press, Basingstoke, UK, 1996, pp. 609, £110.00, (hbk).

\section{William Bains}

This encyclopedia of biological molecules is a puzzle. Is it actually meant to be read, or does the editor agree with Sydney Smith that "No furniture is as charming as books, even if you never open them." For whose education are these words intended? And for whose pocket?

The encyclopedia is the long-playing version of Molecular Biology and Biotechnology, with extended and slightly updated articles on the molecules of life and their medical

William Bains is at PA Consulting Group, Melbourne, Royston, Hertfordshire SG8 6DP, UK (william.bains@pa-consulting.com). importance. The articles are excellent, providing a genuine insight into the topics covered, formulated into a helpful, common structure. How nice, for example, to see an article on the genetics of aging that is not dominated by telomerase or Werner's syndrome, but which treats other experimental systems as sources of insight. Excellent articles on genomes (e.g., Drosophila and mammalian) do not leap straight into contigs and cosmids, and the article on DNA fingerprinting mentions quality assurance long before it lists DNA probe types, as it should. Having all of immunology concisely summarized is a terrific boon to non-immunologists. And so on. The references are slightly dated, tending to peter out at mid-1994. Even these seem in some cases to be last minute additions to update a previously written text. But the value of having a real expert overview the field lies not in trendy citations but the balance they can bring. If there is an article on the topic that interests you here, you are in luck.

However, the articles, excellent thought they are, do not make a whole. Why would you read this? Either to get a thorough background in a subject, or to understand a specific point that you thought interesting but incomprehensible in the pages of Nature Biotechnology or the like. For the latter purpose, the articles are far too dense-harder to read than the article you are trying understand in most cases. For the former use, the book is far from comprehensive. Within each article, coverage is excellent, but there are many gaps. They might be insignificant at (say) an undergraduate level, but they open into conceptual chasms at this level of detail. For example, muta- 